\title{
La integración real de la tecnología en la estrategia de comunicación
}

\author{
Alfredo Cebrián \\ Socio-director de Cuatro Ochenta
}

Los clientes demandan a las agencias nuevos modelos de comunicación más tech. Las agencias demandan a sus equipos ideas más tech. El público demanda a las marcas más... nada. El público no demanda nada a las marcas, está ocupado con su vida. Solo está dispuesto a demandar a las marcas... ante un tribunal.

Los equipos de comunicación navegan y buscan ese gadget, palabro o estrategia cool que edulcore su propuesta, le dé el toque innovador que venda la idea al cliente. Como consecuencia, día a día se lanzan campañas que justifican internamente muy bien el presupuesto y recursos invertidos por el departamento de comunicación y que, además, posiciona de lujo a la agencia en ese nuevo marco de «agencias de perfil tech» o como mínimo agencias a la última. El cliente está encantado porque en la estrategia de su campaña aparece el término «realidad aumentada», geomarketing o «estrategia mobile»; en el comité de dirección alucinan con la presentación del departamento de comunicación. Hasta se oyen voces inmediatas de: «¿Cómo puedo instalarme esto ya en mi móvil?». Si, además, en un alarde de innovación desarrollamos un argumento transmedia, tiene todos los ingredientes para ser una campaña ganadora. ¿Ganadora para quién? Desde luego, la agencia está encantada porque el cliente está encantado y juntos bailan al compás de una danza a la que el público no asiste y, si asiste, lo hace atónito o, peor aún, indiferente. 
En los últimos años vemos cómo la desorientación de los profesionales de la comunicación, ante tanto cambio e innovación en los soportes y formatos unida a las demandas de directivos con poco talento en lo que a desarrollo tecnológico se refiere, producen estrategias, campañas o acciones sin fondo, banales y en las que el único argumento es el uso de la tecnología en sí mismo, aunque sea sin ningún sentido.

Existe la creencia de que el público demanda tecnología, pero es raro ver a un usuario capturar un código QR o verlo pasear por la calle con su móvil delante de las narices disfrutando de una experiencia de realidad aumentada. No porque el código QR no sea una gran idea, sino porque lo que hay detrás del código no llama lo suficiente la atención, no conecta. ¿No será que el público no demanda nada de eso? El público no quiere tecnología por tecnología; no utiliza Whatsapp porque sea un alarde tecnológico, lo utiliza porque fue el sustituto del SMS de pago. Whatsapp fueron y son mensajes de texto gratis; el concepto es sencillo, pero estaba en el foco de lo que realmente anhelaba el público: comunicarse gratis.

El público no utiliza Facebook porque sea la red social más avanzada del mundo. Es la que más penetración obtuvo en menor tiempo y, por lo tanto, en la que más se podía cotillear, deporte internacional donde los haya, y en la que uno más puede hablar de sí mismo, el segundo deporte con más adeptos.

El público, básicamente quiere (queremos) hacer más cosas por menos, hacerlas de forma más sencilla, más divertida o en menos tiempo. Lo que el público quiere en definitiva es ser feliz, una vida más fácil y más eficiente. Parece increíble pero las motivaciones de la gente no han cambiado mucho desde que en 1943 el señor Maslow nos mostrara su pirámide, esa escalera de la vida en la que, en un peldaño u otro, todos nos encontramos.

Entonces, ¿qué podemos hacer para implementar de forma real la tecnología en nuestras estrategias de comunicación? Como primer paso es totalmente necesario olvidarse de la tecnología y volver a pensar en la persona. ¿Son las campañas más tecnológicas las más exitosas? Decididamente, no. Son las que conectan más con la persona y sus motivaciones o necesidades, y aquellas que para impactar con la psique humana se ayudan de la tecnología justa y necesaria. Esas sí que son las que triunfan de verdad. Parece mentira que todo haya cambiado tanto... para que, al final, nada haya cambiado realmente.

La tecnología nos brinda la posibilidad de satisfacer necesidades o expectativas de nuestro público de forma nunca antes vista o en materias impensables hace solo unos pocos años. Pero la tecnología es la herramienta, la solución, y salvo en contadas ocasiones no puede ser la base del mensaje ni el pilar de la comunicación.

La tecnología es el puente que permite llevar a nuestro público a esa experiencia, impacto o sensación basada en factores humanos y no tecnológicos. Incluso 
cuando el propio alarde tecnológico parece la base de una campaña exitosa, esta suele fundamentarse en algo más mundano: el sentido de pertenencia, la necesidad de diferenciación, la vivencia de nuevas experiencias, etc.

Imagino que el primer spot en color fue llamativo por eso, por ser en color. Pero pocos spots en color debieron hacer falta para que de nuevo volviera a recaer en el mensaje el peso del éxito. Hoy la televisión en color se llama app, ibeacon o NFC.

Implementar de forma real la tecnología en una estrategia de comunicación es servirse de ella para llegar allí donde queremos estar o donde queremos llevar a nuestros públicos. Pero cuando se empieza a pensar en cómo hacer una campaña integrando redes sociales, estamos empezando a pensar mal. El proceso creativo debe ser el mismo ahora que el de hace cinco o cien años; son los límites del aterrizaje de ese proceso creativo los que se están ampliando.

Toda idea original debe pulirse para ser trasladada al marco de las realidades viables. Ahora, ese marco se ensancha a una velocidad nunca antes vista y es en ese momento en el que la implantación real y efectiva de la tecnología suma y juega su papel, para llevar más lejos y de forma más cierta el mensaje.

El creativo o el profesional de la comunicación tiene el deber de estar al día en la innovación tecnológica, conocer las últimas herramientas, servirse de ellas y desarrollar alianzas, colaborar con nuevos perfiles profesionales, ingenieros, químicos, informáticos... pero no para crear sopas de palabras de moda en sus planes, sino para conocer mejor que nadie en qué estado se encuentran los límites de lo posible, para que un mensaje potente no se quede en el camino por simple desconocimiento y para desarrollar nuevos códigos de comunicación mucho más allá del verbo.

La tecnología evoluciona para brindarnos la posibilidad de soñar más, eliminando barreras, pero corremos el riesgo de que ante tanto cambio, tanta información y tantas posibilidades, perdamos la perspectiva, nos abrumemos y caigamos en la mediocridad de crear una cuenta en Twitter antes de pensar para qué demonios usarla.

Si me pide que hoy le recomiende la mejor agencia no le diré la que tenga más informáticos, más ordenadores, ni servidores más grandes. La mejor agencia sigue siendo la que tenga la mesa redonda más grande, poblada de creativos, filósofos, ingenieros, artistas, humanistas, marcianos, niños y ancianos... y pilotada por verdaderos profesionales de la comunicación. La que disponga de menos paredes, menos prejuicios y más ganas de comerse la cuenta. No lo dude, esta agencia está preparada para hacer virguerías con la tecnología, aunque no tenga ni un solo ordenador sobre la mesa. 


\section{Referencia de este artículo}

Cebrián, Alfredo (2014). La integración real de la tecnología en la estrategia de comunicación. En: adComunica. Revista Científica de Estrategias, Tendencias e Innovación en Comunicación, $\mathrm{n}^{\circ} 8$. Castellón: Asociación para el Desarrollo de la Comunicación adComunica, Universidad Complutense de Madrid y Universitat Jaume I, 221-224. DOI: http://dx.doi.org/10.6035/2174-0992.2014.8.16. 